\title{
Artificial Lighting Design in The Japan Foundation Library (Case Study: The Japan Foundation Library Design, Jakarta)
}

\author{
Keven Cungiono ${ }^{1}$ Hafidh Indrawan ${ }^{1}$ Mariana Mariana ${ }^{1 *}$
}

\author{
${ }^{1}$ Interior Design Program, Faculty of Visual Art and Design, Universitas Tarumanagara, Jakarta, Indonesia \\ *Corresponding author Email: mariana@fsrd.untar.ac.id
}

\begin{abstract}
Abstract: Japan Foundation is a cultural center dedicated to handling international cultural exchanges through educational activities, Japanese language studies, and so on. A library is an important facility for a Japanese cultural center, it provides the basic to advance information about the culture itself. In designing a library several aspects need to be considered, especially lighting. lighting serves to help visitors to see more clearly, form the impression and image of space, and create an atmosphere. Lighting affects several aspects of space both in terms of atmosphere and visual comfort of the audience. This study used the descriptive qualitative method. This method is used through a study of the types of lighting and lamps used, whether they meet the specified conditions and the role of these lights. In conclusion, in designing interior lighting several factors must be considered, such as lighting requirements (lux) and what impression you want to display, those factors can be fulfilled by choosing the right type of lamp, armature, and the placement of the lamps.
\end{abstract}

Keywords: Lighting, Library, Artificial Lighting

\section{INTRODUCTION}

Japan Foundation is a cultural center located at Summitmas 2, 1st - 2nd Floor Building, J1. Jend. Sudirman Kavling 6162, RT.5 / RW.3, Senayan, Kebayoran Baru, South Jakarta City, Jakarta - 12190. Japan Foundation is a cultural center dedicated to handling international cultural exchanges through educational activities, Japanese language studies, and so on. A library is an important facility for a Japanese cultural center, it provides the basic to advance information about the culture itself.

In designing a library in the cultural center, several important aspects need to be considered, one of which is lighting. lighting serves to help visitors to see more clearly, form the impression and image of space, and create an atmosphere that can increase the interest of visitors to learn about that culture.

\subsection{Artificial Lighting}

Artificial lighting is lighting that is a man-made lighting system that produces light from sources including fire, gaslight, electric lamps, and so on. The function of artificial lighting is not to replace natural lighting but to help the room get the light it needs when natural lighting is insufficient.
To define it technically, "light is the part of the electromagnetic spectrum that can be seen by the human eyes [3]."

The following are some aspects that need to be considered in making artificial lighting designs in the library room.

\subsection{Elements of Light}

According to Kelly the three fundamental elements of light are, (1) Ambient Light or General Lighting, (2) Focal Glow, which is directive light, creates a bright center, and it tells us what to look at, organizes, mark the most important element, (3) Sparkle (play of brilliants), this light attracts human attention, and create a feeling of curiosity, passion, and increase alertness. Play of brilliants can make a distraction or entertainment [4].

\subsection{Lighting Application}

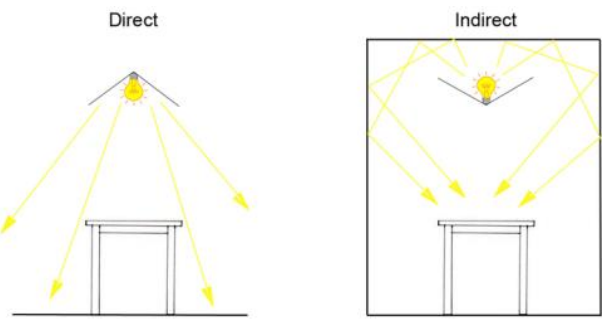

Figure 1 Direct and Indirect Light 
As shown in Figure 1, the application of artificial lighting in the room is divided into two types of application, which are (1) Direct lighting, which provides strong, bold shadows. For example, direct light to the wall will make the room feel spacious and dramatic, (2) Indirect lighting which provides an even, soft light that does not cast shadows in the vertical and horizontal planes. But the similarity of light often causes a room to look monotonous, especially in the white room [8].

\subsection{Indoor Lighting Level Requirements}

Indoor Lighting Level Requirements according to SNI (Indonesian National Standards) SNI-6197:2011 concerning energy conservation in lighting systems. The indoor lighting level requirement for libraries is 300 lux [1].

\subsection{Glare and Visual Comfort}

\section{Direct glare}

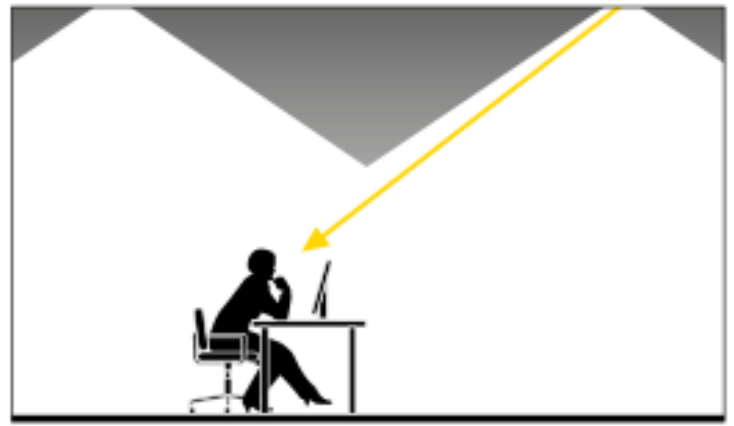

Reflected glare

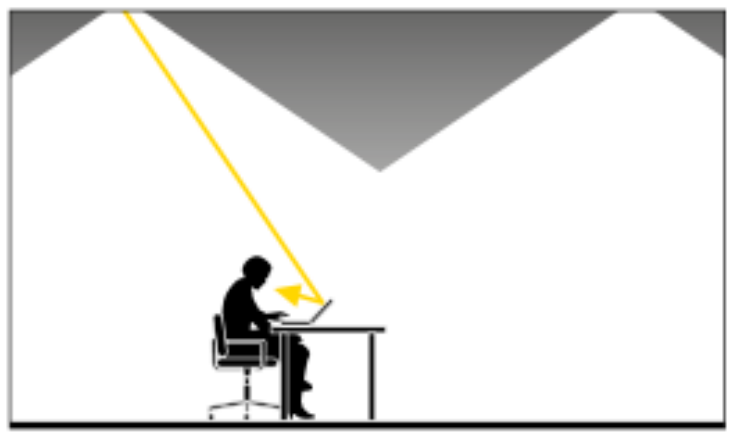

Figure 2 Direct and Indirect Glare

(Source: https://www.wvlight.com/)

According to Gordon "glare is a contrast or excessive lighting and is distracting and annoying" [4]. Based on the type, there are 2 types of glare that are detrimental to visual performance such as, (1) Direct glare, which is caused by the lighting system; it is defined as excessive light misdirected toward the eye. (2) Reflected glare, which is caused by excessive uncontrolled luminance reflected from objects or surfaces in the field of view.

Gordon also said that "the term visual comfort refers to the critical need to eliminate glare and distracting brightness from your field of view" [4]. Visual comfort can be achieved by using a finish or material that has a lower glossiness level, add diffuse transmission material to increase light source diffusion, place lighting outside of the reflected field of view, using the right armature to reduce glare. For example, armature Parabolic reflectors are generally used in general lighting.

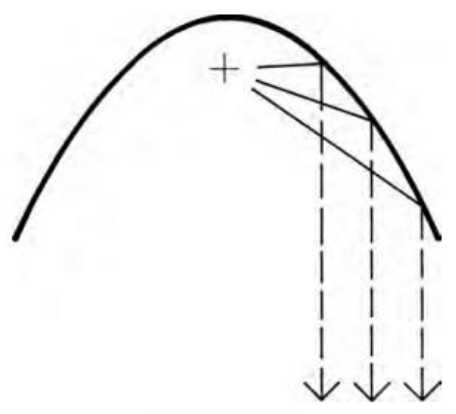

Reflector action

Figure 3 Parabolic Reflector

(Source: Gordon, 2014, PP.162)

\subsection{Impression of Light}

Lighting can give the visual impression of the space that makes a person perceive and behave as the light affects the human being. The effects of artificial lighting on humans are divided into, (1) visual Perception (the perception (interpretation) of human vision when seeing something), (2) visual Impression (the impression when humans see something), (3) visual Imaginary (parables, or visual imagery).[7]

Light can create a certain impression on the environment, by using several ways, such as broad impression, clear impression, relaxing impression, and pleasant impression [8]

\subsection{Color of Light}

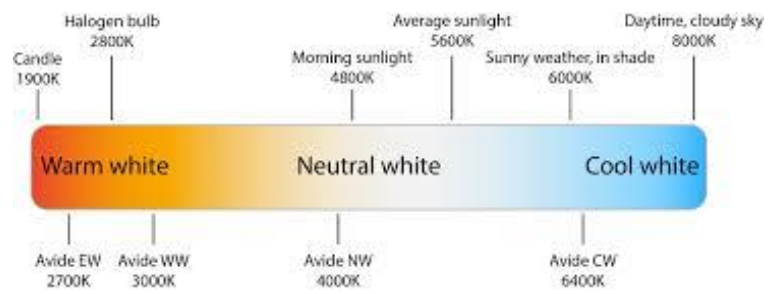

Figure 4 Color Temperature

(Source: https://avidelighting.com/usefulinformation/what-is-color-temperature)

In general, all light sources emit "white light" (with the obvious exception such as colored lamps). It varies according to the type of lamp and the absolute temperature of the laboratory blackbody radiator when its visible radiation matches the color of the light source.

"Color temperature describes how a lamp appears when lighted. Color temperature is measured in kelvin (K), a scale that starts at absolute zero $\left(-273^{\circ} \mathrm{C}\right)[4] . "$ 
The color of light in space also affects human perception. Flynn said, "Visual impression for lighting with a temperature of $4100 \mathrm{~K}$ (cool color temperature) gives an impression of visual clarity, while for lighting with a temperature of $3000 \mathrm{~K}$ (warm color temperature) gives an impression of comfort [4]."

Table 1 The Effect of Lighting Temperature on Human Perception

\begin{tabular}{|c|c|}
\hline Kelvin & Effect \\
\hline $2700 \mathrm{~K}$ & $\begin{array}{l}\text { Ambient } \\
\text { Intimate } \\
\text { Personal }\end{array}$ \\
\hline $3000 \mathrm{~K}$ & $\begin{array}{c}\text { Friendly } \\
\text { Intimate } \\
\text { Cozy }\end{array}$ \\
\hline $3500 \mathrm{~K}$ & $\begin{array}{c}\text { Friendly } \\
\text { Inviting }\end{array}$ \\
\hline $4000 \mathrm{~K}$ & $\begin{array}{c}\text { Neat } \\
\text { Clean } \\
\text { Efficient }\end{array}$ \\
\hline $5000 \mathrm{~K}$ & $\begin{array}{c}\text { Daylight } \\
\text { Vibrant }\end{array}$ \\
\hline $6500 \mathrm{~K}$ & $\begin{array}{c}\text { Daylight } \\
\text { Alert }\end{array}$ \\
\hline
\end{tabular}

Source: https://www.ledrise.eu/blog/color-temperatureexplained-lr/

\subsection{Contrast}

The comparison between ambient light and focal glow determines the level of contrast of a space. Contrast serves to provide a subjective impression (atmosphere) of a space. For example, in a room that receives the same light emphasis in each area, the contrast will be lost. The lost contrast in the space will create a cloudy room atmosphere that makes users feel depressed and lethargic over time. On the other hand, humans will become more energetic and positive when the weather is clear, which is characterized by clear highlights and shadows. This sunny weather scene can be created with a play of contrasts.

According to Gordon, there are two types of contrast environment:

1) Low - contrast environment, is an environment that receives evenly distributed lighting, so there is no hierarchy in a room. A room that has low contrast can make a person feel comfortable, focused, and relaxed. A low contrast environment can be created with a combination of a large proportion of diffuse light and a small amount of focused light.

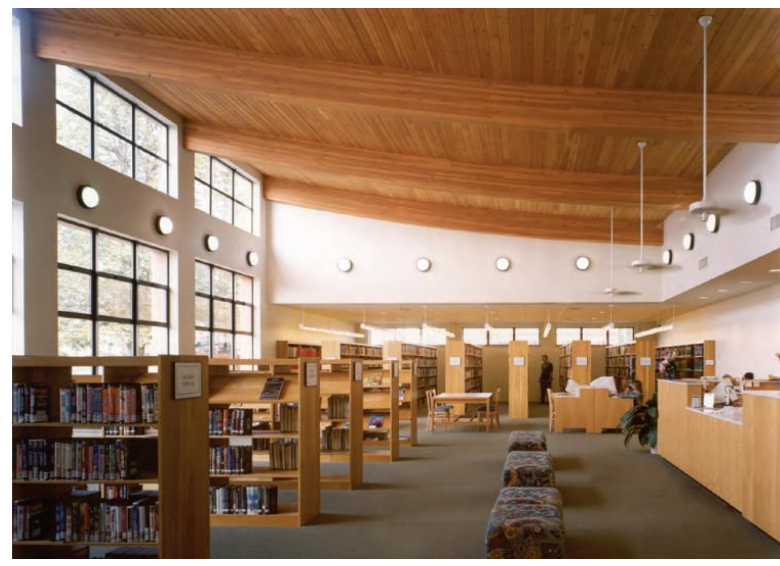

Figure 5 Low - contrast environment (Source: Gordon, 2014, PP.25)

2) High-contrast environment, high-contrast environment space usually used to give the impression of a hierarchy between the object and the background. A space with a high level of contrast is usually used to direct someone to an object or space. A space like this can be created using a combination of a little diffuse light and a lot of focused light [4].

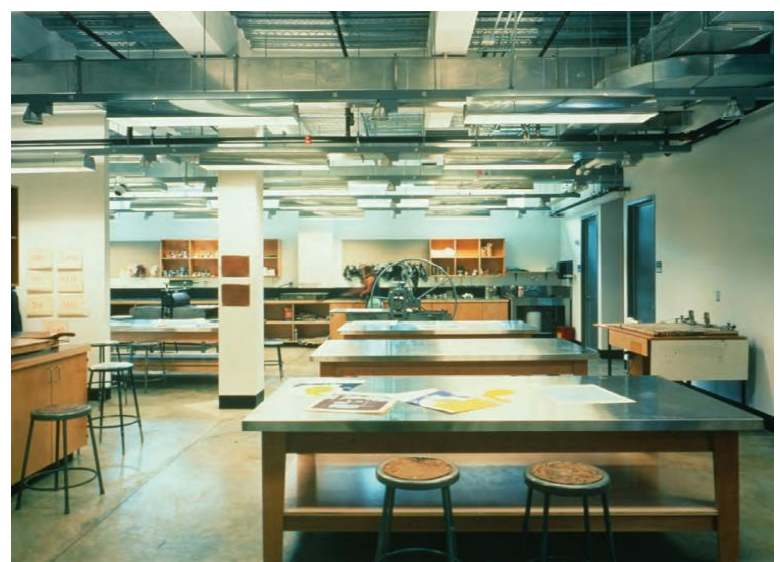

Figure 6 High - contrast environment

(Source: Gordon, 2014, PP.26)

\section{METHOD}

The method used in the process of solving design problems in the interior of the Japan Foundation library is using the Kilmer design process [5], which consists of data collection, data analysis, and conclusions.

Data collection is carried out in literacy from books, journals, and websites regarding the requirements for designing cultural center facilities from a technical and aesthetic aspect.

This study used the descriptive qualitative method. This method is used through a study of the types of lighting and lamps used, whether they meet the specified conditions, and the role of these lights in creating the impression of space. 


\section{RESULTS}

Lighting is an important aspect of an interior design, including the library room. The designer must pay attention to the technical and the purpose of the lighting.

Lighting must be designed following the requirements of SNI, which is 300 lux. So that there is no visual disturbance that will decrease the user's health.

The designer also needs to pay attention to the selection of energy-efficient lamps. Energy-efficient lamps use a small wattage and emit large lumens like LEDs. It also reduces waste from light bulbs and the number of lamps placed.

\subsection{Types of Lamps}

The Artificial Light used in designing this library are:

Table 2 Artificial Lighting

\begin{tabular}{|c|c|c|}
\hline No. & Figure & Explanation \\
\hline 1 & LED Bulb & $\begin{array}{l}\text { General lighting in } \\
\text { this design uses } \\
\text { light bulbs that } \\
\text { have } \\
\text { specifications of } \\
2500 \text { lumens and } \\
2700 \mathrm{~K}\end{array}$ \\
\hline 2 & Pendant Lamp Light & $\begin{array}{l}\text { The lamp used in } \\
\text { the pendant lamp } \\
\text { is a } 6.5 \mathrm{~W} 8402 \mathrm{P} \\
\text { G24d-2 PLC LED } \\
\text { lamp. With } \\
\text { specifications of } \\
650 \text { lumens and } \\
3000 \mathrm{~K}\end{array}$ \\
\hline 3 & 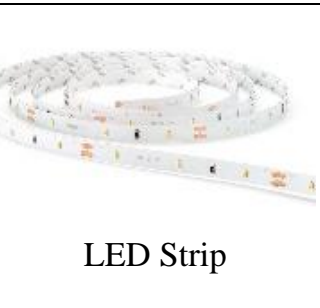 & $\begin{array}{l}\text { For ambiance } \\
\text { lighting, we use } \\
\text { the indirect lamp } \\
\text { technique with } \\
\text { LED strip lights } \\
\text { which have } \\
\text { specifications of } \\
18 \mathrm{~W} \text { and } 3000 \mathrm{~K}\end{array}$ \\
\hline
\end{tabular}

\subsection{General Lighting / Ambient Light}

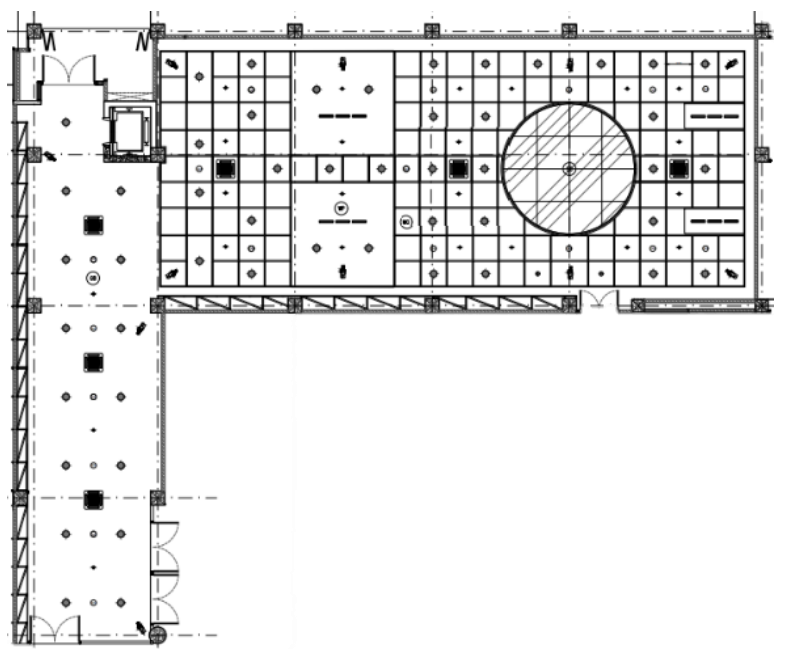

Figure 7 Reflected Ceiling Layout (Source: Keven, 2021)

According to Marilyn "Ambient light is General source of light that uniformly illuminates the entire room, typically from a ceiling fixture or near-ceiling suspended fixture that delivers a large pool of light in space [10]."

The general lighting in this library was designed using an LED bulb with an out-bow type armature with a parabolic reflector as general lighting. The LED lamp used has a lumen of 2500 .

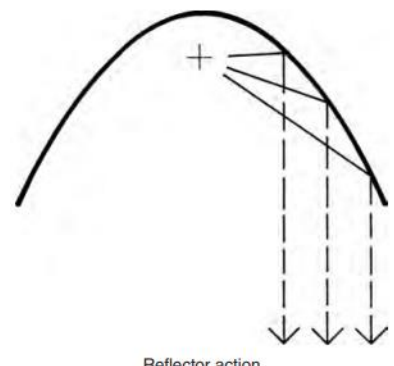

Figure 8 Parabolic Reflector (Source: Gordon, 2014)

Armature with a parabolic reflector is used to control the glare. Armature with a parabolic reflector tends to give an impression of low brightness from normal angles of view because most of the light is directed downward, with minimal light directed toward the eye, and make little reflected luminance that occurs in the cross-view of these reflectors.

The lighting used is distributed to 54 points to achieve a lighting level of 300 lux which is by the Indonesian National Standard on energy conservation in lighting systems (SNI 6197: 2011, 2011). The placement of the lights is based on the level of lumen emitted by the lamp and the utility coefficient of the lamp reflector. 


\subsection{Focal Glow}

According to Gordon "Focal glow is a directive light, creates a bright center, and it tells us what to look at, organizes, mark the most important element [4]." There are 2 types of lighting that act as focal glow elements in this library, which are pendant lights and LED strips.

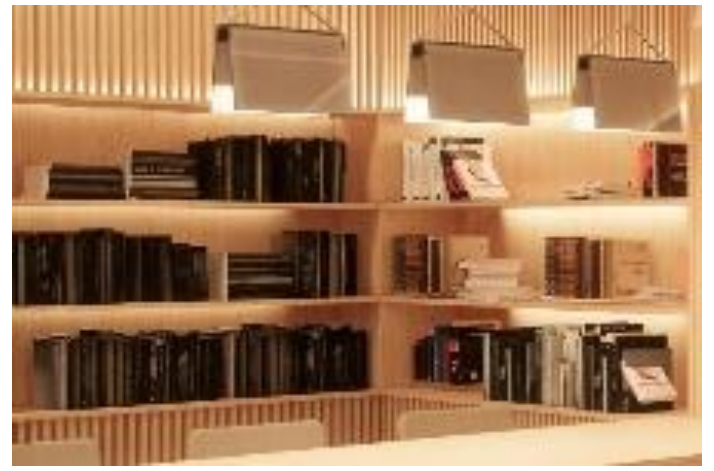

Figure 9 Pendant Lamp Hanging on the Table Top (Source: Keven, 2021)

A pendant lamp is used to highlights the table and helps visitors carry out their activities. It is designed in the shape of a book, to showcase the theme of this cultural center's design, which is Hamonshu book [9]. The armature is made using white acrylic which has a diffuser as a cover to avoid direct glare. The lamp used in the pendant lamp has a specification of 650 lumens that are divided into 3 pendant lamps, so it can reach 300 lux on the surface of the table.

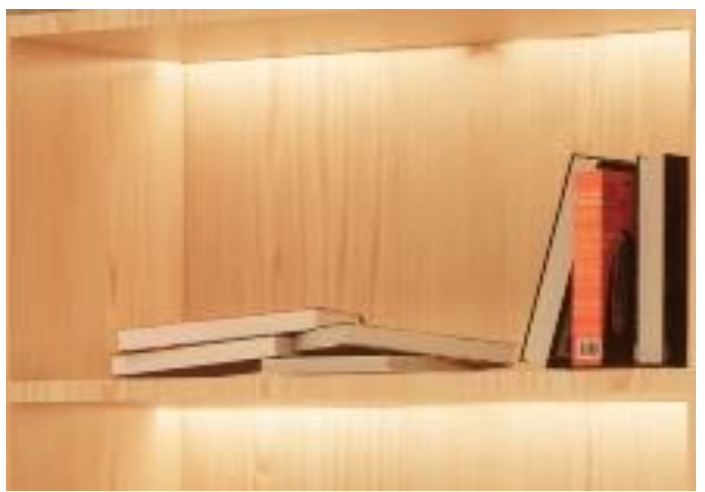

Figure 10 Application of LED Strip on the Bookshelves

(Source: Keven, 2021)

The use of this LED strip serves as a highlight of the mustread book collection in this library and it also gives a welcoming impression to find out more about the Japanese culture.

\subsection{Sparkle}

According to Gordon "Sparkle (play of brilliants), this light attracts human attention, and create a feeling of curiosity, passion, and increase alertness. Play of brilliants can make a distraction or entertainment [4]".

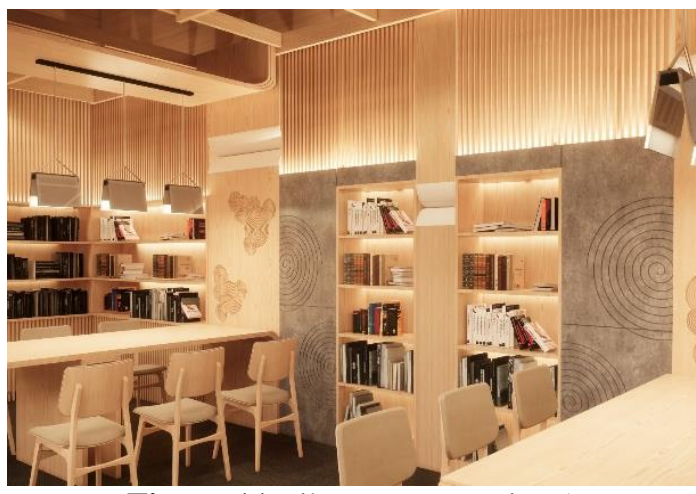

Figure 11 Library Perspective 1

(Source: Keven, 2021)

The sparkle is created by using LED strips to illuminate the grid above the bookshelf to display contrast in the room. This kind of light also excites our eyes and creates a warm and relaxing ambiance for the room.

\subsection{Impression of Light}

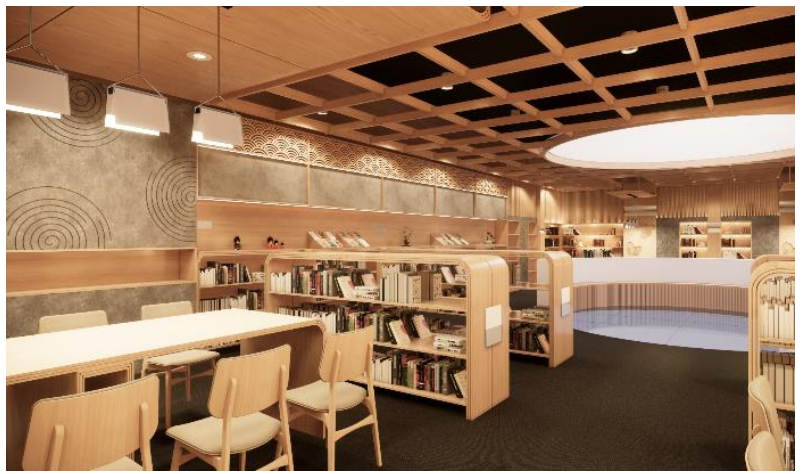

Figure 12 Library Perspective 2

(Source: Keven, 2021)

In this design, the designer wants to create a room that has a warm, relaxing, and welcoming impression to make the visitor feels comfortable, welcome.

Warm and relaxing impressions are created by warm and soft lighting. While welcoming created by a higher contrast at the rear side of the library to encourage visitors to enter and find out more about the Japanese culture. According to Gordon "Attention is involuntarily drawn toward areas of brightness that contrast with the visual background. When a person approaches an unfamiliar space or activity, brightness contrast and color contrast help to establish an initial response and it can be used for guiding the circulation of people entering an unfamiliar room [4]". 


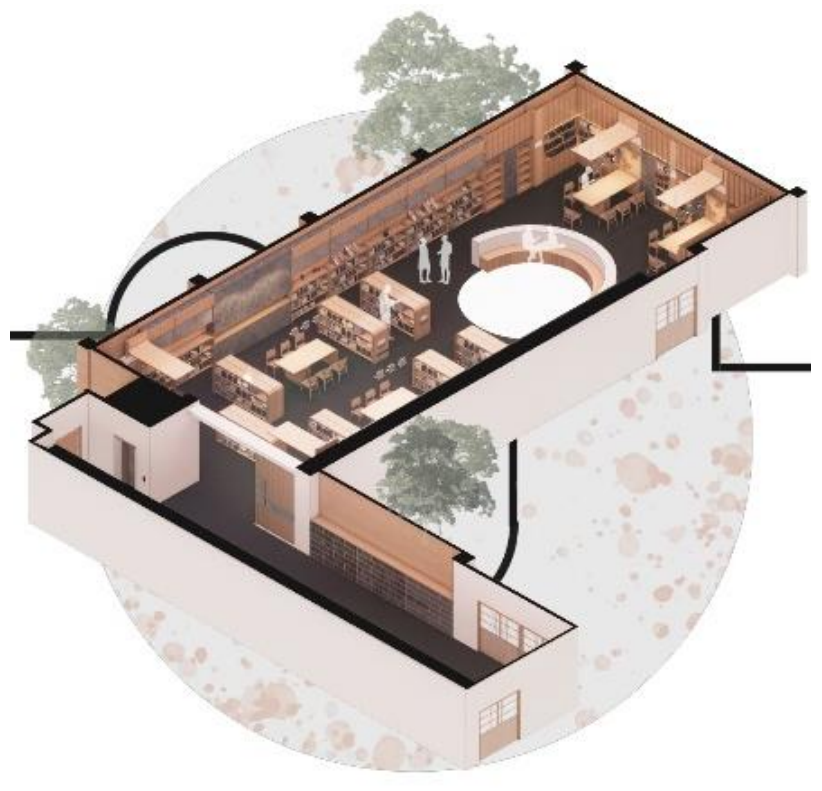

Figure 13 Library Axonometry (Source: Keven, 2021)

\section{CONCLUSION}

Artificial lighting plays an important role in interior design. it supports visitor activities as a support light for natural light to illuminate the room so that visitors can do their activities without distraction. In designing lighting several factors must be considered, such as lighting requirements (lux) and what impression you want to display. To meet the lighting requirements (lux) the designer must pay attention to the type of lamp and its armature. choosing the type of lamp that is not suitable can cause the number of light to be placed and cause the room we are designed to become wasteful of energy. If the lighting does not meet these requirements, it can result in visual discomfort, which can reduce the well-being of the visitor.

Artificial light plays a role in forming the impression of a space. First of all, we have to understand that lighting has different temperatures and emits light that has a different impression. As Flynn said, "Visual impression for lighting with a temperature of $4100 \mathrm{~K}$ (cool color temperature) gives an impression of visual clarity, while for lighting with a temperature of $3000 \mathrm{~K}$ (warm color temperature) gives an impression of comfort [4]." By that statement, we can conclude that to make a visual impression we need to understand it can be concluded that to create a room impression, we need to understand the impact of the temperature of the lamps we use. Other than that, Gordon also said "Contrast serves to provide a subjective impression (atmosphere) of space [4]." Therefore, to create the impression that we want to showcase we need to choose the right type of lamp, and the right amount of contrast. For example, in this design, high contrast in some areas is used to create a welcoming impression, while low contrast in some areas gives the room a relaxing feel.

\section{ACKNOWLEDGMENT}

The author would like to thank the supervisor, Drs. Hafidh Indrawan, M.Sn, and Mrs. Mariana, S.Ds., M.Ars. Who has provided advice and support throughout this design process.

\section{REFERENCES}

[1] Badan Standarisasi Nasional. (2011). SNI-6197:2011 Konservasi Energi pada Sistem Pencahayaan. Jakarta: Badan Standarisasi Nasional.

[2] Cungiono, K. (2021). Perancangan Pusat Kebudayaan The Japan Foundation, Jakarta. Jakarta: Untar.

[3] Entwistle, Jill. (1999). Designing With Light Bars and Restaurants. UK: Roto Vision SA.

[4] Gordon, G. (2014). Interior Lighting for Designers (5 ed.). New Jersey: John Wiley \& Sons, Inc.

[5] Kilmer, R., \& Kilmer, O.W. (2014). Designing Interior. New Jersey: Wiley.

[6] Hidjaz, T. (2004). Terbentuknya Citra dalam Konteks Suasana Ruang. Dimensi Interior, 52.

[7] Pile, J. F. (1980). Interior Design. New York: Harry N. Abrams Inc.

[8] Satwiko, P. (2004). Fisika Bangunan. Yogyakarta: Andi.

[9] Yūzan, M., \& Geisōdō, Y. (1903). Hamonshu: A Japanese Book of Wave and Ripple Designs. Kyōto-shi.

[10] Zelinsky, M. (2006). Complete Lighting Design. USA: Quarry Books. 